\title{
Undiagnosed vertebral hemangioma causing a lumbar compression fracture and epidural hematoma in a parturient undergoing vaginal delivery under epidural analgesia: a case report
}

\section{Un hémangiome vertébral non diagnostiqué provoque une fracture lombaire par compression et un hématome péridural chez une parturiente accouchant par voie vaginale sous analgésie péridurale: une présentation de cas}

\author{
Chryssoula Staikou, MD, PhD • Matthaios Stamelos, MD • \\ Ioannis Boutas, MD • Vassileios Koutoulidis, MD, PhD \\ Received: 25 November 2014/Accepted: 1 April 2015/Published online: 10 April 2015 \\ (C) Canadian Anesthesiologists' Society 2015
}

\begin{abstract}
Introduction Vertebral hemangiomas are benign vascular tumours of the bony spine which are usually asymptomatic. Pregnancy-related anatomical and hormonal changes may lead to expansion of hemangiomas and development of neurological symptoms. We present an unusual case of vertebral fracture due to an undiagnosed hemangioma presenting as postpartum back pain following epidural analgesia.
\end{abstract}

Author contributions Chryssoula Staikou was involved in the conception and design of the manuscript and made critical revisions and edits to the draft. Matthaios Stamelos, Ioannis Boutas, and Vassileios Koutoulidis were involved in data acquisition, and Chryssoula Staikou and Vassileios Koutoulidis were involved in data interpretation. Chryssoula Staikou, Matthaios Stamelos, and Ioannis Boutas were involved in the literature search. Matthaios Stamelos and Ioannis Boutas were involved in drafting the manuscript. Vassileios Koutoulidis was involved in the analysis of the data and made critical revisions to the manuscript.

C. Staikou, MD, PhD ( $\square) \cdot$ M. Stamelos, MD

Department of Anesthesiology, Aretaieio Hospital, Medical

School, University of Athens, 76 Vassilissis Sophias Ave.,

11528 Athens, Greece

e-mail: c_staikou@yahoo.gr

\section{Boutas, MD}

Department of Obstetrics \& Gynecology, Aretaieio Hospital, Medical School, University of Athens, Athens, Greece

V. Koutoulidis, MD, PhD

Department of Radiology, Aretaieio Hospital, Medical School, University of Athens, Athens, Greece
Case presentation A multiparous female with an unremarkable history developed intense lumbar pain after vaginal delivery under epidural analgesia. The pain was attributed to tissue trauma associated with the epidural technique. The patient had no clinical improvement with analgesics, and her symptoms deteriorated over the following days. A magnetic resonance imaging scan revealed an acute fracture of the second lumbar vertebra (L2) with epidural extension and mild compression of the dural sac, suggesting hemangioma as the underlying cause. The patient underwent successful spinal surgery with pedicle screw fixation to stabilize the fracture.

Conclusion Vertebral fractures secondary to acute expansion of a vertebral hemangioma rarely occur during vaginal delivery. In such cases, the labour epidural technique and analgesia may challenge the physician in making the diagnosis. Postpartum severe back pain should be thoroughly investigated even in the absence of neurological deficits, and osseous spinal pathology should be considered in the differential diagnosis.

\section{Résumé}

Introduction Les hémangiomes vertébraux sont des tumeurs vasculaires bénignes de l'épine osseuse et sont généralement asymptomatiques. Les changements anatomiques et hormonaux liés à la grossesse peuvent entraîner l'expansion des hémangiomes et l'apparition de 
symptômes neurologiques. Nous présentons un cas inhabituel de fracture vertébrale due à un hémangiome non diagnostiqué se présentant sous forme de douleur dorsale postpartum après une analgésie péridurale.

Présentation du cas Une femme multipare sans antécédents remarquables a manifesté une douleur lombaire intense après un accouchement vaginal sous analgésie péridurale. La douleur a d'abord été attribuée à un traumatisme tissulaire associé à la technique péridurale. La patiente n'a pas ressenti d'amélioration clinique avec l'administration d'analgésiques, et ses symptômes se sont aggravés au cours des jours suivants. Un examen d'imagerie par résonance magnétique a révélé une fracture aiguë de la deuxième vertèbre lombaire (L2) avec extension péridurale et une compression légère du sac dural, suggérant qu'un hémangiome était la cause sous-jacente. La patiente a subi une chirurgie rachidienne avec succès pour fixer une vis pédiculaire afin de stabiliser la fracture.

Conclusion Les fractures vertébrales secondaires à l'expansion aiguë d'un hémangiome vertébral surviennent rarement pendant les accouchements vaginaux. Dans de tels cas, la technique et l'analgésie péridurale pour le travail obstétrical pourraient compliquer la formulation d'un diagnostic pour le médecin. Il faut rechercher la cause des douleurs dorsales postpartum graves même en l'absence de déficits neurologiques, et il faut tenir compte des pathologies rachidiennes osseuses dans le diagnostic différentiel.

Vertebral hemangiomas are benign vascular tumours in the bony structures of the spine that occur in about $10 \%$ of the general population. ${ }^{1}$ They usually develop within the vertebral bodies and are asymptomatic. Rarely, fastgrowing hemangiomas may extend beyond the vertebra and produce symptoms due to nerve root or spinal cord compression. $^{2}$ Such aggressive progression may occur during pregnancy. The third trimester, in particular, represents a high-risk period where previously asymptomatic vertebral hemangiomas may cause a variety of neurological symptoms such as radicular pain, sensory and motor deficits, even incontinence. ${ }^{3,4}$ The implicated mechanisms include pregnancy-related hemodynamic, mechanical, and hormonal changes which result in vascular distension and growth of these vessel-rich tumours. ${ }^{1}$ Herein, we describe an unusual case of vertebral fracture due to a hemangioma presenting as postpartum back pain following epidural analgesia. The possible mechanisms involved in this complication along with the differential diagnosis and management of such cases are discussed.

\section{Case presentation}

The patient gave written informed consent for this report. A 32-yr-old North African parturient at $40^{+4}$ weeks of gestation was admitted to our hospital in labour. According to her obstetric history, she was gravida 4, para 3 and had undergone three uncomplicated vaginal deliveries without labour epidural analgesia. She was $162 \mathrm{~cm}$ in height and weighed $96 \mathrm{~kg}$; she had gained much more weight during this pregnancy (about $27 \mathrm{~kg}$ ) than during her previous pregnancies. The rest of her medical history and the clinical examination were unremarkable. She had no history of back pain, trauma, or neurological or coagulation disorders. She was not receiving anticoagulants and her laboratory tests and coagulation profile were normal: platelet count, $184,000 \mu \mathrm{L}^{-1}$; international normalized ratio, 1.09; activated partial thromboplastin time, $25.9 \mathrm{sec}$; fibrinogen, $396 \mathrm{mg} \cdot \mathrm{dL}^{-1}$. She had never received general or neuraxial anesthesia.

Three hours after her admission to the delivery suite, the parturient requested epidural analgesia for labour. The epidural space was successfully identified on the third puncture attempt, and a $20 \mathrm{G}$ epidural catheter was inserted through an $18 \mathrm{G}$ Tuohy needle at the clinically estimated level of the L2-L3 interspace. Despite the relative difficulty in identification of the epidural space, the entire procedure was uneventful without resistance to catheter insertion, paresthesia, or signs of vessel injury or leakage of cerebrospinal fluid. A solution of $0.15 \%$ ropivacaine plus fentanyl $2 \mu \mathrm{g} \cdot \mathrm{mL}^{-1}$ at an infusion rate of $10 \mathrm{~mL} \cdot \mathrm{hr}^{-1}$ was used for labour analgesia over the following six hours. No supplementary analgesia was required during that period. The parturient was placed in a lithotomy position for the second stage of labour which lasted $25 \mathrm{~min}$. A healthy neonate weighing $4,200 \mathrm{~g}$ was born via spontaneous vaginal delivery. Following delivery, $2 \%$ lidocaine $7 \mathrm{~mL}$ plus fentanyl $50 \mu \mathrm{g}$ were given epidurally for suturing the vaginal and perineal trauma. Two hours postpartum and in the absence of obstetrical complications, the epidural catheter was removed intact and the patient was transferred to the maternity ward late in the evening. The following morning, the patient complained of intense lumbar pain with movement, especially during mobilization. The differential diagnosis included soft tissue injury/hematoma caused by the Tuohy needle, pelvic girdle pain, ligamentous or muscular stretching due to the lithotomy position, a prolapsed intervertebral disc, space-occupying lesions (e.g., epidural hematoma/ abscess), or infection/meningitis. Clinical examination of the patient's back revealed some local bruising around the epidural puncture site (L2-L4) and tenderness at palpation that aggravated the pre-existing pain and paraspinal muscle spasm. There were no signs of local infection; the patient's 
temperature was normal, and her bladder and bowel function were reported to be normal. Neurological examination dictated no signs of neck stiffness or meningism, no muscle weakness, and no motor or sensory deficits. An anteroposterior pelvic $x$-ray revealed no abnormalities of the sacroiliac joints or diastasis of the symphysis pubis (measured distance $8 \mathrm{~mm}$ ). The pain was attributed to tissue trauma caused by the Tuohy needle during the repeated puncture attempts to identify the epidural space. The patient was placed on bed rest and intravenous analgesics (paracetamol $1 \mathrm{~g} \times 3$, diclofenac $75 \mathrm{mg} \times 2$ ) and was observed closely. Tramadol $75 \mathrm{mg} i v$ was prescribed as a rescue analgesic. The following day, she reported a moderate improvement of her symptoms. Rescue analgesia was not requested. The patient refused to extend her hospital stay or to arrange outpatient follow-up visits at the hospital's Pain Centre due to increased family obligations. She was discharged home on the third day postpartum with written instructions to rest as possible, continue the analgesics per os for a few days, and contact the hospital for possible return and re-evaluation if symptoms persisted or deteriorated.

At home, the patient continued the analgesics per os, but she had no bed rest due to housework duties and childcare. Even though her symptoms were worsening over the following days, she was reluctant to return to hospital due to family issues. Finally, she presented to the Emergency Department of our hospital on the sixth day postpartum. Her condition had deteriorated significantly, and she could not stand up or walk without assistance due to excruciating lumbar pain. She was readmitted to hospital for further investigation and management. Tramadol $75 \mathrm{mg} i v$ was given for pain relief and a neurological consultation was requested. Neurological examination showed normal deep tendon reflexes and superficial and proprioceptive sensation. An urgent MRI scan revealed the presence of an acute compression fracture of the L2 vertebra with associated soft tissue hematoma $(0.3 \times 2 \mathrm{~cm})$ in the anterior epidural space causing mild thecal sac compression. Reinforced vertical trabeculae were suggestive of hemangioma (Figure).

The patient was transferred to the Department of Spine Surgery at a cooperating orthopedic hospital for further management. According to the clinical and radiological findings, the size of the hematoma was small and there was no neurological compromise due to compression. The main concern was the mechanical instability of the spine caused by the vertebral fracture. Thus, surgical stabilization was performed via a minimally invasive posterior approach and pedicle screw fixation from L1- L3. Preoperative embolization of the hemangioma was not considered necessary because no major hemorrhage was anticipated during surgery. The postoperative course was

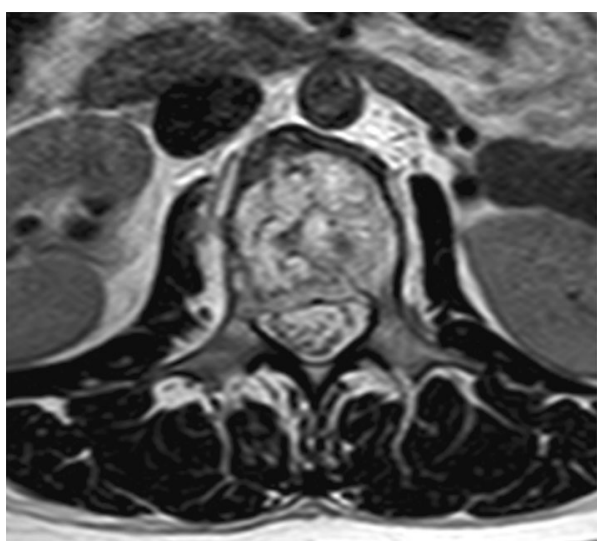

Figure Axial T2-weighted image of the lumbar spine at the level of L2 shows a high- signal-intensity fracture with associated soft tissue/ hematoma in the anterior epidural space causing mild thecal sac compression

uncomplicated; the patient's low back pain improved significantly immediately after the operation, and she experienced a rapid functional recovery with early mobilization. Further routine follow-up was scheduled at six weeks and at three and six months. At follow-up, the patient was neurologically intact and fully ambulatory. She reported no low back pain and had returned to her normal daily activities.

\section{Discussion}

Vertebral hemangiomas represent the most common benign tumours of the spine. ${ }^{5}$ They are usually underdiagnosed due to the absence of symptoms. In females, radicular pain and neurological deficits associated with vertebral hemangiomas may develop during pregnancy. ${ }^{4,5}$ Compression of the inferior vena cava by the gravid uterus and elevation of intra-abdominal pressure enhance the blood flow through the vertebral venous plexus. This mechanism, along with a 30-50\% increase in circulating blood volume, may gradually lead to expansion of an existing vertebral hemangioma. ${ }^{1}$ Another implicated factor is possibly maternal progesterone which affects venous distensibility; moreover, estrogens may contribute to the enlargement of vertebral hemangiomas via their growth effects on endothelium. ${ }^{6}$

The rapidly increasing size of hemangiomas during pregnancy can cause narrowing of the spinal canal and compression of the spinal cord, fracture of the involved vertebral body, epidural hematoma, and spinal cord ischemia. $^{7,8}$ In the case we present, the patient was multiparous, and compared with her previous pregnancies, the increased body weight and the large fetus size could have played a role in further raising the 
intra-abdominal pressure and enhancing the blood flow to the hemangioma. Additionally, the lithotomy position combined with the valsalva maneuvers applied during the second stage of labour probably produced an acute expansion of the vertebral hemangioma, which led to the compression fracture of the involved vertebra. Regarding the epidural hematoma, it could have developed concurrently with the fracture, but it is also possible that mechanical instability caused bleeding from the hypervascular fractured vertebra during mobilization and activity. ${ }^{9}$ Diclofenac might have played a role in this sequela via impairment of platelet function.

Regarding fracture pathophysiology, vertebral hemangiomas cause diffuse bone infiltration and consequently reduced bone density. The lesions are characterized by erosion of the horizontal trabeculae, thus resulting in the typical radiographic finding of accentuated thickened vertical trabeculae. ${ }^{2}$ Rarely, their enlargement within the vertebral body may produce expansion of the vertebra and pathological fracture. ${ }^{2}$ Hemodynamic changes, as those occurring during pregnancy, may play a significant role, ${ }^{6}$ while mechanical factors, such as bending and axial vertebral loading, can also contribute. ${ }^{9}$

Magnetic resonance imaging is the imaging modality of choice to show the aggressive characteristics of symptomatic hemangiomas, such as the presence and extent of extraosseous soft tissue, the compression of the spinal cord and/or nerve roots, and the presence of epidural hematoma. ${ }^{2}$ In our case, an acute compression fracture with epidural extension was diagnosed, while the presence of low-signal-intensity reinforced trabeculae in the vertebral body were suggestive of hemangioma as the underlying cause.

Initially, the condition of our patient was clinically misdiagnosed, and the pain was attributed to tissue trauma caused by the Tuohy needle. In that case, a significant improvement of symptoms would be expected with bed rest and analgesics. The deterioration of symptoms alerted the physicians, and an MRI confirmed the final diagnosis. In our patient, the absence of previous symptoms, the use of an epidural technique, and the relative improvement with simple analgesics in the first few days along with the unremarkable neurological examination misled the initial clinical diagnostic approach and probably masked the true cause.

Regarding other possible causes included in the differential diagnosis, the lack of neurological symptoms and findings, the normal temperature, and the absence of local signs of infection made the possibility of epidural hematoma, abscess, or meningitis less likely. Epidural hematoma is commonly characterized by weakness of the lower extremities, while sensory deficits and bowel and bladder dysfunction may also be present. Epidural abscess is usually accompanied by local infection at the epidural site and fever, while in some cases, back pain and neurological signs are also found. ${ }^{10}$ For both complications, clinical suspicion is the indication for imaging with a computed tomography (CT) scan or an MRI, with the latter being the method of choice. ${ }^{10}$ Early consultation with a neurologist, neurosurgeon, and infectious disease specialist is required for diagnosis, assessment of condition severity, and finally, decisionmaking regarding conservative or surgical treatment. ${ }^{10}$ Meningitis is characterized by high fever (in the case of microbial infection), severe headache, nausea/vomiting, mental confusion, agitation, and signs of meningeal irritation (e.g., neck stiffness), while in some cases, the patient may even develop seizures. ${ }^{11}$ Cerebrospinal fluid analysis is required to confirm the diagnosis. None of the above manifestations were found in our patient. Another possible diagnosis could be disc herniation occurring or exacerbated during pregnancy and parturition. Symptomatology of a prolapsed disc includes back pain and/or sciatica, muscle weakness, and sensory abnormalities, such as paresthesia. $^{12}$ The anatomical lesion is confirmed by a CT or MRI scan. ${ }^{12}$ Our patient had negative history and an unremarkable neurological examination; moreover, bed rest combined with analgesics and anti-inflammatory drugs would be expected to improve her symptoms.

It is noteworthy that the incidence of back pain during the first week after labour has been reported as high as 40$45 \% .^{13}$ According to the literature, early postpartum back pain may be associated with several common or rare conditions which are presented in the Table. ${ }^{10-14}$

No specific guidelines exist for the optimal treatment of symptomatic vertebral hemangiomas during pregnancy. Management is case sensitive and requires a multidisciplinary approach, since it depends on the severity of maternal symptoms and fetal gestational age. Chi et al. recommend observation if gestational age is less than 32 weeks and symptoms are mild or moderate, while prepartum embolization and/or surgery should be performed in the presence of severe neurological symptomatology. ${ }^{1}$ In the latter case, there is a possibility of spontaneous induction of preterm delivery with a high risk of neonatal morbidity and/or mortality. Also, fetal exposure to radiation during angiography and embolization should be considered. ${ }^{1}$ If gestational age is 36 weeks or more and maternal clinical condition is stable, close observation until delivery and postpartum therapeutic interventions (surgery, radiation, embolization) are suggested as the safest options. ${ }^{1}$ In the presence of worsening symptoms, induction of labour or Cesarean delivery followed by embolization or surgery is proposed. The decision-making is probably more difficult for 
Table Differential diagnosis of early postpartum back pain

\begin{tabular}{|c|c|}
\hline Possi & nt \\
\hline $\begin{array}{l}\text { Trauma caused by the epidural needle/catheter } \\
\text { - Trauma/edema in ligaments/muscles/periosteum } \\
\text { - Subcutaneous/soft tissue hematoma at puncture site } \\
\text { - Epidural hematoma } \\
\text { Trauma/mechanical stress due to position/delivery } \\
\text { - Stretching of ligaments/relaxation of back muscles due to epidural } \\
\text { analgesia } \\
\text { - Unnatural positions facilitated by a dense sensory block } \\
\text { - Trauma during positioning for delivery/faulty lithotomy position } \\
\text { - Vertebral joints' trauma by fast delivery } \\
\text { - Pelvic girdle pain/sacroiliac joint syndrome due to pregnancy-induced } \\
\text { relaxation of pelvic articulations } \\
\text { Exacerbation of pre-existing spinal pathology } \\
\text { - Disc herniation } \\
\text { - Degenerative lesions/osteoporosis } \\
\text { - Lumbar lordosis associated with pregnancy } \\
\text { - Back pain due to pregnancy weight gain and relaxin effects } \\
\text { Inflammation/ infection } \\
\text { - Local at puncture site } \\
\text { - Meningitis/ central nervous system infections } \\
\text { Osseous pathology } \\
\text { - Sacral stress fractures (fatigue or insufficiency fractures due to } \\
\text { pregnancy-induced osteoporosis) }\end{array}$ & $\begin{array}{l}\text { 1. Initial clinical approach/assessment } \\
\text { - History } \\
\text { - Symptoms and signs/Clinical examination } \\
\text { - Examination of painful area } \\
\text { - Pain localization/ radicular radiation } \\
\text { - Instability } \\
\text { - Motor and sensory deficits } \\
\text { - Alterations in reflexes } \\
\text { - Alterations in bladder/rectal sphincter tone (up to incontiner } \\
\text { - Signs of meningism } \\
\text { 2. Consultation with a specialist according to initial findings } \\
\text { - Neurologist } \\
\text { - Neurosurgeon } \\
\text { - Orthopedic surgeon } \\
\text { - Infectious disease clinician } \\
\text { - Psychiatrist } \\
\text { 3. Radiographic imaging of spine and pelvis as indicated } \\
\text { - Plain x-ray } \\
\text { - Computed tomography scanning } \\
\text { - Magnetic resonance imaging } \\
\text { - Angiography } \\
\text { 4. Management/referral } \\
\text { - Symptomatic treatment } \\
\text { - Analgesia as required } \\
\text { - Immobilization/stabilization }\end{array}$ \\
\hline
\end{tabular}

pregnancies of 32-36 weeks. ${ }^{15}$ Chi et al. recommend observation for females with stable condition and prepartum surgery only in cases with paraplegia due to severe spinal cord compression. If surgery is considered, the risks of preterm spontaneous delivery and intraoperative exposure to radiation should also be taken into account. ${ }^{1,15}$ In selected cases, a Cesarean delivery followed by spine surgery may represent a safe alternative option. $^{15}$

Regarding surgical treatment of vertebral hemangiomas, decompressive surgery is performed in cases with significant neurological symptomatology; ${ }^{16}$ a laminectomy or a radical resection via corpectomy or vertebrectomy can be performed. Transarterial embolization of hemangioma feeding vessels can be used as single therapy in selected cases or as preoperative preparation in the presence of large hemangiomas where massive hemorrhage is expected during surgery. ${ }^{16}$ Percutaneous vertebroplasty is a relatively new minimally invasive method that causes destruction of the hemangioma via cement injection. ${ }^{16,17}$ Patients with pain but without neurological deficit may be good candidates for embolization or vertebroplasty. ${ }^{16}$ Radiation therapy may be used to prevent extravertebral growth of the hemangioma. It is usually applied to painful lesions, while postoperative irradiation has traditionally been an adjuvant to subtotal tumour resection. ${ }^{16}$ Intralesional injection of ethanol has also been used with positive results. ${ }^{16}$ In the present case, there was no neurological deficit, but pain and local mechanical 
instability were present due to a vertebral fracture. The stabilization surgery performed to restore the structural integrity of the bony spine has been described in similar cases. $^{18}$

In conclusion, asymptomatic vertebral hemangiomas may rarely expand acutely to produce vertebral fractures and epidural hematomas during vaginal delivery. In such cases, the labour epidural technique and analgesia may challenge the physician in making the diagnosis. Postpartum severe back pain should be thoroughly investigated even in the absence of neurological deficits, and osseous spinal pathology should be considered in the differential diagnosis.

Acknowledgements We sincerely thank A. Melemeni, A. Hatziioannou, and A. Vadalouka for their assistance and support in the case management.

Funding Funding sources supporting the submitted work: None.

Conflict of interest The authors have no commercial or noncommercial affiliations that are or may be perceived to be a conflict of interest with this work.

\section{References}

1. Chi JH, Manley GT, Chou D. Pregnancy-related vertebral hemangioma. Case report, review of the literature, and management algorithm. Neurosurg Focus 2005; 19: E7.

2. Gaudino $S$, Martucci $M$, Colantonio $R$, et al. A systematic approach to vertebral hemangioma. Skeletal Radiol 2015; 44: 2536.

3. Bandiera S, Gasbarrini A, De Iure F, Cappuccio M, Picci P, Boriani $S$. Symptomatic vertebral hemangioma: the treatment of 23 cases and a review of the literature. Chir Organi Mov 2002; 87: 1-15.

4. Yuksel M, Yuksel KZ, Tuncel D, Zencirci B, Bakaris S. Symptomatic vertebral hemangioma related to pregnancy. Emerg Radiol 2007; 13: 259-63.
5. Tekkok IH, Açikgoz B, Saglam S, Onol B. Vertebral hemangioma symptomatic during pregnancy-report of a case and review of the literature. Neurosurgery 1993; 32: 302-6.

6. Schwartz TH, Hibshoosh H, Riedel CJ. Estrogen and progesterone receptor - negative T11 vertebral hemangioma presenting as a postpartum compression fracture: case report and management. Neurosurgery 2000; 46: 218-21.

7. Vijay $K$, Shetty AP, Rajasekaran S. Symptomatic vertebral hemangioma in pregnancy treated antepartum. A case report with review of literature. Eur Spine J 2008; 17(Suppl 2): S299303.

8. Robbins LR, Fountain EM. Hemangioma of cervical vertebras with spinal-cord compression. N Engl J Med 1958; 258: 685-7.

9. Vinay S, Khan SK, Braybrooke JR. Lumbar vertebral haemangioma causing pathological fracture, epidural haemorrhage, and cord compression: a case report and review of literature. J Spinal Cord Med 2011; 34: 335-9.

10. Cameron CM, Scott DA, McDonald WM, Davies MJ. A review of neuraxial epidural morbidity: experience of more than 8,000 cases at a single teaching hospital. Anesthesiology 2007; 106: 997-1002.

11. Vasquez CE, Pereira Rda R, Tomita T, Bedin A, Castro RA. Meningitis after combined spinal-epidural analgesia for labor: case report (Portuguese). Rev Bras Anestesiol 2002; 52: 330-4.

12. Forster MR, Nimmo GR, Brown AG. Prolapsed intervertebral disc after epidural analgesia in labour. Anaesthesia 1996; 51: 773-5.

13. Russell R. Epidural analgesia and back pain. Curr Anaesth Crit Care 1995; 6: 212-7.

14. Beltran LS, Bencardino JT. Lower back pain after recently giving birth: postpartum sacral stress fractures. Skeletal Radiol 2011; 40(461-2): 481-2.

15. Inamasu J, Nichols TA, Guiot BH. Vertebral hemangioma symptomatic during pregnancy treated by posterior decompression, intraoperative vertebroplasty, and segmental fixation. J Spinal Disord Tech 2006; 19: 451-4.

16. Acosta FL Jr, Dowd CF, Chin C, Tihan T, Ames CP, Weinstein PR. Current treatment strategies and outcomes in the management of symptomatic vertebral hemangiomas. Neurosurgery 2006; 58 : 287 95.

17. Hao $J, H u Z$. Percutaneous cement vertebroplasty in the treatment of symptomatic vertebral hemangiomas. Pain Physician 2012; 15: 43-9.

18. Moles A, Hamel O, Perret C, Bord E, Robert R, Buffenoir K. Symptomatic vertebral hemangiomas during pregnancy. J Neurosurg Spine 2014; 20: 585-91. 